\title{
Prevalence of renal and hepatobiliary disease, laboratory abnormalities, and potentially toxic medication exposures among persons with COPD
}

Douglas W Mapel'

Jenõ P Marton²

'Lovelace Clinic Foundation, Albuquerque, New Mexico, NM, USA; ${ }^{2} \mathrm{Health}$ Economics and Outcomes Research, Pfizer Inc, New York, NY, USA
Correspondence: Douglas W Mapel Lovelace Clinic Foundation, 2309 Renard Place SE, Suite 103, Albuquerque, NM 87106-4264, USA

$\mathrm{Tel}+\mathrm{I} 5059389900$

Fax + I 5059389940

Email dmapel@comcast.net

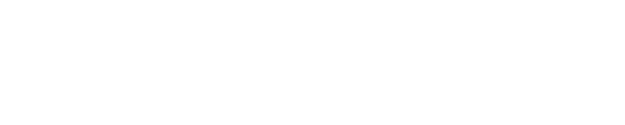

Background: The purpose of this study was to describe the prevalence of renal and hepatic disease, related laboratory abnormalities, and potentially hepatotoxic and nephrotoxic medication use in a population-based cohort of persons with chronic obstructive pulmonary disease (COPD).

Methods: This was a retrospective case-control cohort analysis of COPD patients enrolled in one regional health system for at least 12 months during a 36-month study period $(n=2284)$. Each COPD patient was matched by age and gender to up to three persons not diagnosed with COPD ( $\mathrm{n}=5959)$.

Results: The mean age for cases and controls was 70.3 years, and $52.5 \%$ were women. The COPD cohort had significantly higher prevalences (cases/100) of acute, chronic, and unspecified renal failure as compared with controls ( 1.40 versus $0.59,2.89$ versus 0.79 , and 1.09 versus 0.44 , respectively). Among the cases, $31.3 \%$ had at least one renal or urinary tract diagnosis during the study period, as compared with $21.1 \%$ of controls. COPD cases also had more gallbladder disease (2.76 versus 1.63 ) and pancreatic disease ( 1.40 versus 0.60$)$, but not hepatic disease. COPD patients were more likely to have at least one serum creatinine level (5.1 versus 2.1) or liver aspartate aminotransferase level (4.5 versus 2.7$)$ that was more than twice the upper limit of normal. COPD patients had prescription fills for an average of 17.6 potentially nephrotoxic and 27.4 hepatotoxic drugs during the study period, as compared with 13.6 and 19.9 for the controls $(P$ value for all comparisons $<0.01)$.

Conclusion: COPD patients have a substantially increased prevalence of renal, gallbladder, and pancreatic diseases, as well as abnormal renal and hepatic laboratory values, but not diagnosed liver disease. COPD patients are also more likely to be prescribed medications with potentially toxic renal or hepatic side effects.

Keywords: chronic obstructive pulmonary disease, kidney diseases, liver diseases, epidemiology, toxicology, health care utilization

\section{Introduction}

One of the difficulties of evaluating the safety of new medications for chronic obstructive pulmonary disease (COPD) is the high prevalence of comorbid conditions. A recent study of Medicare beneficiaries in the US found that $32.7 \%$ of COPD patients had at least one other major chronic illness, and $39.0 \%$ had two or more. ${ }^{1}$ Although COPD is among the leading causes of death worldwide, few published data are available on the incidence and prevalence of specific comorbid illnesses, particularly renal and hepatic disease. COPD patients with known renal or hepatic disease are often excluded from 
clinical trials, and those who are found to have undiagnosed asymptomatic elevations in renal function tests or hepatic transaminases during screening are also usually excluded. Therefore, the post-marketing surveillance for treatment safety among COPD patients in the general population is problematic because of the lack of epidemiology on the prevalence of renal and hepatic disease.

Further complicating the mission of monitoring new drug safety is the fact that COPD patients are more likely than non-COPD patients to take a variety of prescription medications. In one survey, we found that COPD patients used approximately 50\% more cardiovascular agents than age-matched and gender-matched controls, and almost twice as many antibiotics, analgesics, and psychotherapeutics. ${ }^{2}$

The purpose of this project is to describe the prevalence of renal and hepatic diseases and related laboratory abnormalities in a population-based cohort of COPD patients and compare these rates with age-matched and gender-matched controls. We also describe the utilization of potentially renotoxic or hepatotoxic prescription drugs in these cohorts.

\section{Materials and methods}

\section{Study site}

This study was conducted among members of the Lovelace Health Plan (LHP), a regional health insurance company that provides a range of commercial employer-sponsored, health maintenance organization, preferred provider organization, and Medicare or Medicaid managed care products. The LHP is a component of Lovelace Health Systems, an integrated medical system based in Albuquerque, NM, USA, which includes four hospitals and a network of outpatient clinics. The LHP served approximately 240,000 members annually during the study period (2005-2008). Most LHP clients, as ascertained by self-report on annual surveys during the study period, live in urban areas, and $38.7 \%$ are Hispanic, $55.8 \%$ are non-Hispanic white, $2.1 \%$ are Native American, and 3.4\% are other racial designations.

\section{Study subjects}

The COPD patients identified for this study had to meet each of the following criteria: be aged 40 years or older at the start of the study period; have at least two outpatient visits on separate days or at least one hospitalization associated with an ICD-9 code consistent with COPD [491.x (chronic bronchitis); 492.x (emphysema); or 496 (COPD)]; and be continuously enrolled in the LHP for at least 12 months during the 3 -year study period. We have shown this system for identifying COPD patients to be more than $95 \%$ accurate in two previous projects using the LHP database. ${ }^{3,4}$ Patients aged 90 years or older at the beginning of the study period, or who could not be matched to at least one individual without COPD by age and gender, were excluded. Those diagnosed with alpha-1 antitrypsin deficiency were also excluded. The control group was created by randomly selecting for each COPD patient up to three LHP members of the same age and gender who did not have any diagnosis of COPD, but had a similar duration of enrollment ( \pm 2 months). This project was approved and supervised by the institutional review board for Lovelace Health Systems.

\section{Capture of renal and hepatic diagnoses}

To identify diagnosed renal and hepatic diseases in the COPD and control cohorts, we surveyed the database for any utilization associated with an ICD-9 code consistent with renal or urinary tract disease $(580 . x-599 . x)$ or hepatobiliary/pancreatic disease (070.x, 570.x-577.x). Patients were required to have the same renal or hepatic disease code on two outpatient visits on separate days, or during one hospitalization, to avoid the problem of "ruleout" diagnoses.

\section{Capture of nephrotoxic and hepatotoxic drugs}

All medications dispensed to patients in either the COPD or control populations during the study period were captured. Drugs were identified as being potentially nephrotoxic or hepatotoxic if these precautions were listed as common or potentially serious side effects for these agents as included in their monograph in the Physicians' Desk Reference. ${ }^{5}$

\section{Stratification of COPD by complexity}

One of the secondary aims of this project was to see whether there was an association between COPD severity and the prevalence of hepatic or renal laboratory abnormalities. We were also interested in whether utilization of potentially nephrotoxic or hepatotoxic medications increased with COPD complexity. Spirometry results are not included in the LHP database, so we used a classification method that stratifies COPD patients by their COPD-related health care utilization. ${ }^{6}$ Patients who were admitted to the hospital primarily for complications of COPD, or who had $\geq 20$ outpatient encounters for COPD during the study period, were designated high complexity. Patients who had between five and 19 outpatient encounters for COPD but were never admitted to the hospital were designated as moderate complexity. The rest of the COPD patients in the cohort were 
designated as low complexity. This system divided the COPD cohort into three relatively equal groups. We have found in our previous work in this cohort that COPD utilization was a significant but weak correlate with the degree of airflow obstruction, although increased utilization was in fact a better predictor of poor clinical outcomes. ${ }^{4}$

\section{Statistical analysis}

The McNemar test for paired proportions was used to compare COPD case and non-COPD control cohorts for differences in renal and hepatobiliary diagnoses. Laboratory abnormalities were compared using the Chi-square test. The Wilcoxon ranksum test was used to compare mean prescription fills. A $P$ value of 0.05 or less was designated as statistically significant. All data processing and computations were performed using SAS $^{\circledR}$ statistical software (SAS Institute Inc, Windows Desktop version 9.3, Cary, NC, USA).

\section{Results}

A total of 2284 persons met all the criteria to be included as COPD patients for this study. Their mean ( \pm standard deviation) age was $70.3 \pm 9.8$ years, and $52.5 \%$ were women. A total of 1412 patients were matched to three controls, 851 could be matched to only two controls, and 21 patients could be matched to only one control. Only three COPD patients could not be matched to a control, and were thus excluded from this analysis.

COPD patients were significantly more likely than their controls to have a diagnosis of renal or urinary tract disease (Table 1). A total of 714 COPD patients had 827 different renal or urinary tract diagnoses, as compared with 1260 control patients with 1494 diagnoses. Chronic renal failure was more than three times more prevalent among COPD patients $(2.89 \%)$ than among controls $(0.79 \%)$. Acute renal failure was also significantly more common among COPD patients $(1.40 \%)$ than the controls $(0.59 \%)$.

COPD patients did not have an increased prevalence of diagnosed liver parenchymal diseases (cirrhosis, hepatitis, or other chronic conditions, Table 2). However, they did have a significantly increased prevalence of gallbladder disease (2.76\% in COPD versus $1.63 \%$ of controls, $P<0.001)$ and pancreatic disease $(1.40 \%$ versus $0.60 \%, P<0.001)$.

COPD patients were significantly more likely to have renal or hepatic laboratory testing and more likely to have abnormal tests (Table 3). Approximately $14 \%$ of the COPD patients had at least one abnormal liver function test and at least $29 \%$ had an abnormal renal test, versus $10 \%$ and $17 \%$ for their controls, respectively. We did not find a significant relationship between the prevalence of hepatic laboratory abnormalities and COPD complexity. Patients with high and moderate COPD complexity were more likely to have a blood urea nitrogen test that was more than twice the upper limit of normal $(9.0 \%, 7.1 \%$, and $5.0 \%$ for high, moderate, and low complexity, respectively, $P<0.05$ ). However, there was no significant correlation between COPD complexity and elevation in serum creatinine.

COPD patients had substantially more prescription medication fills, including those that are potentially harmful to the kidneys or liver (Table 4). The greatest differences between COPD and controls in terms of potentially nephrotoxic drug exposure were seen in the central nervous system and electrolyte categories. In terms of potentially hepatotoxic drugs, the greatest differences were found in these same categories, plus antibiotics and anti-infective agents.

We did not find a significant correlation between COPD complexity and any of the specific hepatic or renal ICD-9 diagnoses (data not shown). The total number of prescription fills did vary by COPD complexity [mean fills during the study period: low (145.9), moderate (178.6), and high (198.7), $P<0.001]$. Correspondingly, the mean total number of fills for potentially nephrotoxic $(15.0,17.9$, and 20.2) and hepatotoxic $(23.2,28.0$, and 32.1) medications also increased by COPD complexity $(P<0.01$ for all differences).

\section{Discussion}

We found that COPD patients had approximately twice the incidence of acute renal failure, and three times the prevalence of diagnosed chronic renal failure than did the age-matched and gender-matched controls. Elevations in renal function tests were also common: $27.1 \%$ of the COPD cohort had at least one abnormal creatinine level during the study period as compared with $16.7 \%$ of controls. Some of this difference may be attributable to exposure to potentially nephrotoxic medications in that COPD patients averaged 17.6 prescription fills for potentially nephrotoxic agents as opposed to 13.6 fills for controls. However, some of the difference in renal disease could be due to the higher prevalence of cardiovascular disease and other chronic medical conditions that we have already demonstrated in this COPD population. ${ }^{2,4}$

We did not find an increased prevalence of diagnosed liver disease among COPD patients, but they were significantly more likely to have gallbladder disease or pancreatic disease. COPD patients did have a higher prevalence of abnormal liver function tests, with $12.1 \%$ having at least one abnormal aspartate aminotransferase test during the 3-year study period versus $6.9 \%$ of the controls. COPD patients were 
Table I Prevalence of renal disease in chronic obstructive pulmonary disease cases and controls

\begin{tabular}{|c|c|c|c|}
\hline Condition (ICD-9 code) & $\begin{array}{l}\text { Cases } \\
(n=2284)\end{array}$ & $\begin{array}{l}\text { Controls } \\
(n=5959)\end{array}$ & $P$ value \\
\hline \multicolumn{4}{|l|}{ (580-599.x; excluding 588)* } \\
\hline Acute glomerulonephritis (580.x) & I (0.04) & $2(0.03)$ & 0.828 \\
\hline Nephrotic syndrome (58I.x) & $6(0.26)$ & $4(0.07)$ & 0.022 \\
\hline Chronic glomerulonephritis (582.x) & I (0.04) & I (0.02) & 0.481 \\
\hline Nephritis and nephropathy (583.x) & $26(1.14)$ & $46(0.77)$ & 0.110 \\
\hline Acute renal failure (584.x) & $32(1.40)$ & $35(0.59)$ & $<0.001$ \\
\hline Chronic renal failure $(585 . x)$ & $66(2.89)$ & $47(0.79)$ & $<0.001$ \\
\hline Renal failure, unspecified (586) & $25(1.09)$ & $26(0.44)$ & $<0.001$ \\
\hline Renal sclerosis, unspecified (587) & $0(0.00)$ & I (0.02) & 0.530 \\
\hline Disorders secondary to renal disease $(588)$ & $17(0.74)$ & $15(0.25)$ & $<0.001$ \\
\hline Kidney infections (590.x) & $7(0.31)$ & $8(0.13)$ & 0.101 \\
\hline Hydronephrosis (59I) & $9(0.39)$ & II (0.18) & 0.084 \\
\hline Calculi of kidney and ureter (592.x) & $36(1.58)$ & $98(1.64)$ & 0.826 \\
\hline Other disorders of ureter (593.x) & $180(7.88)$ & $218(3.66)$ & $<0.001$ \\
\hline Calculus of lower tract (594.x) & $5(0.22)$ & $8(0.13)$ & 0.386 \\
\hline Cystitis (595.x) & $9(0.39)$ & $15(0.25)$ & 0.283 \\
\hline Other disorders of bladder (596.x) & $28(1.23)$ & $67(1.12)$ & 0.699 \\
\hline Urethritis (597.x) & $0(0.00)$ & $5(0.08)$ & 0.166 \\
\hline Urethral stricture (598.x) & $8(0.35)$ & $15(0.25)$ & 0.448 \\
\hline Other disorders of the urinary tract (599.x) & $37 \mid(16.2)$ & $872(14.6)$ & 0.068 \\
\hline \multicolumn{4}{|l|}{ Subtypes of 599.x } \\
\hline 599.0 urinary tract infection & $297(\mid 3.0)$ & $702(11.8)$ & 0.128 \\
\hline 599.2 urethral diverticulum & $\mathrm{I}(0.04)$ & I $(0.02)$ & 0.481 \\
\hline 599.3 urethral caruncle & $0(0.00)$ & $2(0.03)$ & 0.381 \\
\hline 599.4 urethral false passage & $0(0.00)$ & $3(0.05)$ & 0.284 \\
\hline 599.6 urinary obstruction, NOS & $6(0.26)$ & $3(0.05)$ & 0.009 \\
\hline 599.7 hematuria & $105(4.60)$ & $248(4.16)$ & 0.382 \\
\hline 599.8 other specified disorders & $2(0.09)$ & $6(0.10)$ & 0.864 \\
\hline 599.9 other unspecified & $5(0.22)$ & $8(0.13)$ & 0.386 \\
\hline
\end{tabular}

Notes: *Patients may have more than one renal or urinary tract diagnosis. Values expressed as the number of patients and percent (cases/I00) of the COPD or control cohort. Disease categories without a patient in either cohort were not listed.

Abbreviation: NOS, not otherwise specified.

also significantly more likely to be treated with potentially hepatotoxic medications, with the average COPD patient receiving a mean 27.4 prescription fills for potentially hepatotoxic drugs versus 19.9 for the controls.

The significance of this study is that it demonstrates that renal diseases, as well as abnormal renal function tests, are relatively common among COPD patients in the general population. COPD patients also have increased liver enzyme abnormalities, gallbladder disease, and pancreatic disease, although the prevalence of diagnosed liver disease was not increased. These are potentially important considerations in the clinical management of all COPD patients, especially for

Table 2 Diagnosed hepatic, gallbladder, and pancreatic diseases among chronic obstructive pulmonary disease cases and controls

\begin{tabular}{|c|c|c|c|}
\hline & $\begin{array}{l}\text { Cases } \\
(n=2284)\end{array}$ & $\begin{array}{l}\text { Controls } \\
(n=5959)\end{array}$ & $P$ value \\
\hline $\begin{array}{l}\text { Total patients with any hepatic diagnosis* } \\
(070 . x, 570-573 . x)\end{array}$ & $25(1.09)$ & $66(1.11)$ & 0.96 \\
\hline Viral hepatitis including hepatitis $A, B$, or C (070.x) & $10(0.44)$ & $30(0.50)$ & 0.67 \\
\hline Acute and subacute hepatic necrosis (570.x) & $0(0.00)$ & $2(0.03)$ & 0.38 \\
\hline Alcohol-related liver diseases (57I.I-0.3) & $4(0.18)$ & II (0.18) & 0.93 \\
\hline Non-alcohol related liver diseases (57I.4-0.9) & $10(0.44)$ & $32(0.54)$ & 0.57 \\
\hline Abscess and other liver infections $(572.0,572.1,573.1-573.3)$ & $4(0.18)$ & $8(0.13)$ & 0.75 \\
\hline All gallbladder disease including cholelithiasis (574.x-576.x) & $63(2.76)$ & $97(1.63)$ & $<0.001$ \\
\hline All pancreatic disease (577.x) & $32(1.40)$ & $36(0.60)$ & $<0.001$ \\
\hline
\end{tabular}

Notes: Values expressed as the number of patients and percent (cases/100) of the chronic obstructive pulmonary disease cases or controls. *Patients may have more than one specific hepatic diagnosis. 
Table 3 Prevalence of laboratory abnormalities among COPD cases and controls

\begin{tabular}{|c|c|c|c|c|}
\hline Test & & $\begin{array}{l}\text { No tests } \\
\text { obtained }\end{array}$ & $\begin{array}{l}\text { One or more } \\
\text { tests-all normal }\end{array}$ & $\begin{array}{l}\text { One or more tests- } \\
\text { at least one elevated }\end{array}$ \\
\hline \multicolumn{5}{|l|}{ Liver function tests } \\
\hline Alkaline phosphatase & $\begin{array}{l}\text { COPD } \\
\text { Control }\end{array}$ & $\begin{array}{l}* 311(13.6) \\
1292(21.7)\end{array}$ & $\begin{array}{l}* 1659(72.6) \\
4104(68.9)\end{array}$ & $\begin{array}{l}* 314(13.7) \\
563(9.45)\end{array}$ \\
\hline $\begin{array}{l}\text { Alkaline phosphatase } \\
\qquad(>2 \times \text { Upper limit } n l)\end{array}$ & $\begin{array}{l}\text { COPD } \\
\text { Control }\end{array}$ & $\begin{array}{l}* 311(13.6) \\
1292(21.7)\end{array}$ & $\begin{array}{l}* 1929(84.5) \\
4572(76.7)\end{array}$ & $\begin{array}{l}44(1.9) \\
95(1.6)\end{array}$ \\
\hline ALT (SGPT) & $\begin{array}{l}\text { COPD } \\
\text { Control }\end{array}$ & $\begin{array}{l}* 326(14.3) \\
1227(20.6)\end{array}$ & $\begin{array}{l}* 1757(76.9) \\
4392(73.7)\end{array}$ & $\begin{array}{l}* 201(8.8) \\
340(5.7)\end{array}$ \\
\hline $\begin{array}{l}\text { ALT (SGPT) } \\
\quad(>2 \times \text { Upper limit } n l)\end{array}$ & $\begin{array}{l}\text { COPD } \\
\text { Control }\end{array}$ & $\begin{array}{l}* 326(14.3) \\
1227(20.6)\end{array}$ & $\begin{array}{l}* 1886(82.6) \\
4622(77.6)\end{array}$ & $\begin{array}{l}* 72(3.2) \\
110(1.8)\end{array}$ \\
\hline $\begin{array}{l}\text { AST (SGOT) } \\
\quad(>\text { Upper limit nl) }\end{array}$ & $\begin{array}{l}\text { COPD } \\
\text { Control }\end{array}$ & $\begin{array}{l}* 300(13.1) \\
1235(20.7)\end{array}$ & $\begin{array}{l}* 1707(74.7) \\
4313(72.4)\end{array}$ & $\begin{array}{l}* 277(12.1) \\
411(6.90)\end{array}$ \\
\hline AST (SGOT) & COPD & $* 300(13.1)$ & $* 1880(82.3)$ & $* 104(4.5)$ \\
\hline$(>2 \times$ Upper limit $n l)$ & Control & $1235(20.7)$ & $4563(76.6)$ & $161(2.7)$ \\
\hline $\begin{array}{l}\text { Total bilirubin } \\
\text { (> Upper limit nl) }\end{array}$ & $\begin{array}{l}\text { COPD } \\
\text { Control }\end{array}$ & $\begin{array}{l}* 308(13.2) \\
1294(21.7)\end{array}$ & $\begin{array}{l}* 1725(75.5) \\
4165(69.9)\end{array}$ & $\begin{array}{l}* 251(11.0) \\
500(8.39)\end{array}$ \\
\hline $\begin{array}{l}\text { Total bilirubin } \\
\qquad(>2 \times \text { Upper limit } n l)\end{array}$ & $\begin{array}{l}\text { COPD } \\
\text { Control }\end{array}$ & $\begin{array}{l}* 308(13.2) \\
1294(21.7)\end{array}$ & $\begin{array}{l}* 1924(84.2) \\
4575(76.8)\end{array}$ & $\begin{array}{l}+52(2.3) \\
90(1.5)\end{array}$ \\
\hline $\begin{array}{l}\text { LDH } \\
\qquad(>\text { Upper limit nl) }\end{array}$ & $\begin{array}{l}\text { COPD } \\
\text { Control }\end{array}$ & $\begin{array}{l}* 2132(93.9) \\
5779(97.0)\end{array}$ & $\begin{array}{l}* 97(4.2) \\
124(2.0)\end{array}$ & $\begin{array}{l}* 55(2.4) \\
56(0.9)\end{array}$ \\
\hline $\begin{array}{l}\mathrm{LDH} \\
\qquad(>2 \times \text { Upper limit } \mathrm{nl})\end{array}$ & $\begin{array}{l}\text { COPD } \\
\text { Control }\end{array}$ & $\begin{array}{l}* 2132(93.9) \\
5779(97.0)\end{array}$ & $\begin{array}{l}* 146(6.4) \\
161(2.7)\end{array}$ & $\begin{array}{l}6(0.2) \\
19(0.3)\end{array}$ \\
\hline $\begin{array}{l}\text { Amylase } \\
\qquad(>\text { Upper limit } \mathrm{nl})\end{array}$ & $\begin{array}{l}\text { COPD } \\
\text { Control }\end{array}$ & $\begin{array}{l}* 1410(61.7) \\
4678(78.5)\end{array}$ & $\begin{array}{l}* 799(35.0) \\
1187(19.9)\end{array}$ & $\begin{array}{l}* 75(3.3) \\
94(1.6)\end{array}$ \\
\hline Amylase & COPD & $* 1410(61.7)$ & $* 848(37.1)$ & $26(1.1)$ \\
\hline$(>2 \times$ Upper limit $\mathrm{nl})$ & Control & $4678(78.5)$ & $1249(20.9)$ & $32(0.5)$ \\
\hline \multicolumn{5}{|l|}{ Renal function tests } \\
\hline Blood urea nitrogen & COPD & $* 237(10.4)$ & $* 1395(61.1)$ & *652 (28.5) \\
\hline (>Upper limit nl) & Control & $1044(17.5)$ & $3970(66.2)$ & $945(15.8)$ \\
\hline Blood urea nitrogen & COPD & $* 237(10.4)$ & *1895 (83.0) & *152 (6.7) \\
\hline$(>2 \times$ Upper limit $\mathrm{nl})$ & Control & $1044(17.5)$ & $4762(79.9)$ & $153(2.6)$ \\
\hline $\begin{array}{l}\text { Creatinine } \\
\text { (>Upper limit nl) }\end{array}$ & $\begin{array}{l}\text { COPD } \\
\text { Control }\end{array}$ & $\begin{array}{l}* 221(9.68) \\
954(16.0)\end{array}$ & $\begin{array}{l}* 1445(63.3) \\
4008(67.3)\end{array}$ & $\begin{array}{l}* 618(27.1) \\
997(16.7)\end{array}$ \\
\hline Creatinine & COPD & $* 221$ (9.68) & *1946 (85.2) & $* 117$ (5.I) \\
\hline$(>2 \times$ Upper limit $n l)$ & Control & $954(16.0)$ & $4878(81.9)$ & $127(2.1)$ \\
\hline
\end{tabular}

Notes: Values expressed as the number of patients and row percent of the COPD or control group. *Difference between COPD and control significant $(P<0.0 \mathrm{I})$. Abbreviations: ALT, alanine aminotransferase; AST, aspartate aminotransferase; COPD, chronic obstructive pulmonary disease; ULN, upper limit of normal; LDH, lactate dehydrogenase; SGOT, serum glutamic oxaloacetic transaminase; SPGT, serum glutamic pyruvate transaminase.

those who may be initiating a new medication with potential hepatic or renal toxicity. Traditionally, renal function and hepatic disease testing are not standard components of COPD patient evaluation, and it is possible that a substantial number of renal and hepatic disease cases are undiagnosed. Therefore, if a patient does develop disease or laboratory abnormalities after initiation of a new treatment, it can be very difficult to know whether it is due to a previously undiagnosed chronic renal or hepatic condition, a side effect of the new medication, or some combination of both. Furthermore, COPD patients in our cohort had 59\% more prescription fills overall, plus substantially more fills of known potentially nephrotoxic and hepatotoxic medications, so the potential for harmful medication interactions is also greater.

The results of pulmonary function tests were not available for this study, so we were not able to stratify the population by the severity of airflow obstruction or the newer GOLD (Global Initiative for Chronic Obstructive Lung Disease) staging system. We did stratify the COPD patients into thirds based on respiratory disease utilization, reasoning that persons with advanced COPD are more likely to have increased health care utilization. However, there were no significant associations between COPD complexity and diagnosed liver disease or elevated hepatic enzymes. We did review the medical records of all COPD patients with hepatic disease, and a history of alcohol abuse was documented in $25 \%$. However, we were not able to examine the medical records of controls, so the significance of this finding is uncertain.

Other COPD cohort studies have found a high prevalence of comorbidities, but there are few that have specifically examined hepatic disease. A case-control analysis of 1388 
Table 4 Mean prescription fills during the three-year study period among chronic obstructive pulmonary disease cases and matched controls

\begin{tabular}{|c|c|c|c|}
\hline & All drugs & $\begin{array}{l}\text { Potentially } \\
\text { nephrotoxic }\end{array}$ & $\begin{array}{l}\text { Potentially } \\
\text { hepatotoxic }\end{array}$ \\
\hline \multicolumn{4}{|c|}{ Anti-infectives and antibiotics } \\
\hline COPD & $* 8.7(11.8)$ & $* 2.4(4.5)$ & *6.3 (8.7) \\
\hline Control & $5.1(9.0)$ & $1.6(3.3)$ & $3.3(6.0)$ \\
\hline \multicolumn{4}{|c|}{ Antineoplastics } \\
\hline COPD & $0.9(5.3)$ & $0.3(4.5)$ & $0.6(4.4)$ \\
\hline Control & $0.8(5.2)$ & $0.3(3.3)$ & $0.5(4.3)$ \\
\hline \multicolumn{4}{|c|}{ Autonomic agents } \\
\hline COPD & $* 20.4(31.6)$ & 0 & t0.5 (3.1) \\
\hline Control & $2.6(8.4)$ & 0 & $0.4(2.6)$ \\
\hline \multicolumn{4}{|c|}{ Blood formation and anticoagulation } \\
\hline COPD & $* 2.9(\mid 1.0)$ & 0 & $* 1.2(4.5)$ \\
\hline Control & I.5 (7.0) & 0 & $0.7(3.4)$ \\
\hline \multicolumn{4}{|c|}{ Cardiovascular } \\
\hline COPD & $* 35.6(49.4)$ & $* 9.6(17.4)$ & $* 12.4(23.9)$ \\
\hline Control & $30.3(45.9)$ & $8.7(17.3)$ & II.3 (22.6) \\
\hline \multicolumn{4}{|c|}{ Central nervous system agents } \\
\hline COPD & $* 32.7(50.6)$ & $* 11.3(11.3)$ & $* 12.4(22.0)$ \\
\hline Control & $18.8(34.4)$ & $8.2(16.2)$ & $7.6(15.8)$ \\
\hline \multicolumn{4}{|c|}{ Electrolytic, caloric, and water balance } \\
\hline COPD & $* 13.9(25.9)$ & $* 4.7(8.6)$ & $* 5.7(14.0)$ \\
\hline Control & $7.3(18.3)$ & $2.6(6.4)$ & $2.1(8.8)$ \\
\hline \multicolumn{4}{|c|}{ Gastrointestinal drugs } \\
\hline COPD & $* 8.1(15.6)$ & t0.14 (1.9) & $* 4.1(10.5)$ \\
\hline Control & $5.4(13.4)$ & $0.07(1.7)$ & $2.8(9.2)$ \\
\hline \multicolumn{4}{|c|}{ Hormones (natural and synthetic) } \\
\hline COPD & $* 23.1(33.5)$ & $0.03(0.6)$ & $* 4.5(13.4)$ \\
\hline Control & I7.6 (30.5) & $0.01(0.8)$ & $4.9(13.6)$ \\
\hline \multicolumn{4}{|c|}{ Unclassified therapeutics } \\
\hline COPD & $6.5(15.8)$ & $0.1(2.2)$ & 0 \\
\hline Control & $4.6(13.0)$ & $0.1(2.7)$ & 0 \\
\hline \multicolumn{4}{|c|}{ Eye, ear, nose, and throat preparations } \\
\hline COPD & $3.9(10.1)$ & 0 & $0.10(1.2)$ \\
\hline Control & $3.7(10.3)$ & 0 & $0.09(0.9)$ \\
\hline \multicolumn{4}{|l|}{ Total } \\
\hline COPD & $* 169.6(154)$ & $* 17.6(18.5)$ & $* 27.4(28.2)$ \\
\hline Control & $106.7(116)$ & $13.6(15.5)$ & $19.9(22.9)$ \\
\hline
\end{tabular}

Notes: Values expressed as the mean (standard deviation). $* P<0.01 ;{ }^{\dagger} P<0.05$.

Abbreviation: COPD, chronic obstructive pulmonary disease.

Medicaid beneficiaries with COPD reported a higher prevalence of mild liver disease as compared with matched controls $(2.95 \%$ versus. $1.59 \% ; P<0.05)$, but the difference in moderate or severe liver disease did not reach statistical significance $(0.79 \%$ versus $0.36 \%) .^{7}$ In a large cohort of persons from the United Kingdom who were free of diagnosed hepatobiliary disease, higher levels of bilirubin were associated with a slightly lower risk of COPD $(6 \%$ decrease in risk per $0.1 \mathrm{mg} / \mathrm{dL}$ increase in serum bilirubin level). ${ }^{8}$ In a study of 666 persons with chronic disease in Japan, $13.8 \%$ of those with chronic liver disease had undiagnosed airflow obstruction as compared with 9.0\% of those who did not, yielding an odds ratio of $2.10(95 \%$ confidence interval 1.23-3.57) after adjustment for age, gender, and smoking history. ${ }^{9}$ Another analysis of a small cohort of persons with chronic hepatitis $\mathrm{C}$ found evidence of accelerated decline in forced expiratory volume in one second and diffusing capacity of lung for carbon monoxide at a rate similar to that of smokers without hepatitis $\mathrm{C}$, and additive affects on decline among those with hepatitis $\mathrm{C}$ who continued to smoke. ${ }^{10}$

There is also scant published information on the association between COPD and renal disease. In a study of 508 current and ex-smokers who had detailed renal function studies, pulmonary function testing, and computed tomography scan analysis, there was a strong correlation between glomerular 
filtration rate and the extent of emphysema, but not percent predicted forced expiratory volume in one second or other measures of airflow obstruction. ${ }^{11}$ In a retrospective analysis of 3358 vascular surgery patients from The Netherlands, the prevalence of COPD was inversely related to kidney function, with COPD present in $47 \%, 38 \%$, and $32 \%$ of patients with an estimated glomerular filtration rate $<60$, 60-89, and $\geq 90 \mathrm{~mL} / \mathrm{min} / 1.73 \mathrm{~m}^{2}$, respectively. ${ }^{12}$ In a study of 433 ambulatory COPD patients from Norway, the prevalence of undiagnosed chronic renal failure (glomerular filtration rate $<60$ ) was $9.6 \%$ in women and $5.1 \%$ in men. ${ }^{13}$ In a study of 288 hospitalized COPD patients from Italy, chronic renal failure was cited as a comorbidity in $26.3 \%$ of the cohort, but it was never cited as a primary cause for their admission. ${ }^{14}$

This project has important limitations that should be noted. The greatest limitations are those that are common to all observational studies. In this cohort, all laboratory testing and labeling of patients with diagnoses is done solely at the discretion of their treating physician, and it is highly likely that there is great variability from physician to physician about when laboratory testing is obtained and how diagnoses are made. Some of this variability may explain the discrepancy between the relatively high prevalence of abnormal laboratory tests and low prevalence of diagnosed renal and hepatic disease. Data obtained from other cohorts where practice patterns are different may be expected to have different prevalences than we have observed. However, differences in practice patterns are unlikely to account fully for the substantial differences between the COPD and control cohorts. Similarly, they would not explain the substantial increase in dispensing of all drugs, including nephrotoxic and hepatotoxic agents, among COPD patients. Variability in patient's health care-seeking behavior may have also affected our results. For example, patients who are reticent about seeking medical attention could have few opportunities for the diagnosis of renal or hepatic abnormalities. Our cohorts were all members of one health plan in one geographic region, so financial barriers or regional variations in access to care should not have been major limitations. Finally, the association between COPD and renal or hepatic disease may be confounded by the high prevalence of other comorbidities, such as coronary artery disease and congestive heart failure, which have an increased prevalence among COPD patients.

COPD patients are at risk for a spectrum of comorbid complications, most importantly those other diseases that are also strongly related to cigarette smoking such as heart disease and cancer. Renal and hepatic abnormalities, while less obvious and typically more transient, may also be common and have important implications on new therapies. The potential for nephrotoxicity and hepatotoxicity should be kept in mind by clinicians treating patients with COPD when initiating new therapies and when considering the risk/ benefit characteristics of pharmacologic interventions.

\section{Acknowledgments}

The authors wish to thank Scott Robinson, Leila Nelson, and Eva Lydick for their assistance with data management and analyses.

\section{Disclosure}

This research was supported by a grant from Pfizer Pharmaceuticals Inc. Jeno P Marton was an employee of Pfizer Inc. at the time of study conduct. Douglas W Mapel discloses no conflicts of interest in this work.

\section{References}

1. Schneider KM, O’Donnell BE, Dean D. Prevalence of multiple chronic conditions in the United States' Medicare population. Health Qual Life Outcomes. 2009;7:82.

2. Mapel DW, Hurley JS, Frost FJ, Petersen HV, Picchi MA, Coultas DB. Health care utilization in chronic obstructive pulmonary disease. A case-control study in a health maintenance organization. Arch Intern Med. 2000;160(17):2653-2658.

3. Mapel DW, Picchi MA, Hurley JS, et al. Utilization in COPD: patient characteristics and diagnostic evaluation. Chest. 2000;117(5 Suppl 2) 346S-353S

4. Mapel DW, McMillan GP, Frost FJ, et al. Predicting the costs of managing patients with chronic obstructive pulmonary disease. Respir Med. 2005;99(10):1325-1333.

5. [No authors listed]. PDR Guide to Drug Interactions, Side Effects, and Indications. Montvale, NJ: Thomson PDR; 2006.

6. Mapel DW, Dutro MP, Marton JP, Woodruff K, Make B. Identifying and characterizing COPD patients in US managed care. A retrospective, cross-sectional analysis of administrative claims data. BMC Health Serv Res. 2011;11:43.

7. Lin PJ, Shaya FT, Scharf SM. Economic implications of comorbid conditions among Medicaid beneficiaries with COPD. Respir Med. 2010;104(5):697-704.

8. Horsfall LJ, Rait G, Walters K, et al. Serum bilirubin and risk of respiratory disease and death. JAMA. 2011;305(7):691-697.

9. Minakata Y, Ueda H, Akamatsu K, et al. High COPD prevalence in patients with liver disease. Intern Med. 2010;49(24):2687-2691.

10. Kanazawa H, Hirata K, Yoshikawa J. Accelerated decline of lung function in COPD patients with chronic hepatitis $\mathrm{C}$ virus infection: a preliminary study based on small numbers of patients. Chest. 2003;123(2):596-599.

11. Chandra D, Stamm JA, Paleversusky PM, et al. The relationship between pulmonary emphysema and kidney function in smokers. Chest. 2012;142(3):655-662.

12. van Gestel YR, Chonchol M, Hoeks SE, et al. Association between chronic obstructive pulmonary disease and chronic kidney disease in vascular surgery patients. Nephrol Dial Transplant. 2009; 24(9):2763-2767.

13. Gjerde B, Bakke PS, Ueland T, Hardie JA, Eagan TM. The prevalence of undiagnosed renal failure in a cohort of COPD patients in western Norway. Respir Med. 2012;106(3):361-366.

14. Terzano C, Conti V, Di Stefano F, et al. Comorbidity, hospitalization, and mortality in COPD: results from a longitudinal study. Lung 2010;188(4):321-329. 


\section{Publish your work in this journal}

The International Journal of COPD is an international, peer-reviewed journal of therapeutics and pharmacology focusing on concise rapid reporting of clinical studies and reviews in COPD. Special focus is given to the pathophysiological processes underlying the disease, intervention programs, patient focused education, and self management protocols.

This journal is indexed on PubMed Central, MedLine and CAS. The manuscript management system is completely online and includes a very quick and fair peer-review system, which is all easy to use. Visit http://www.dovepress.com/testimonials.php to read real quotes from published authors.

Submit your manuscript here: http://www.dovepress.com/international-journal-of-copd-journal 